\title{
Design of a Conceptual Framework of Performance Improvement of Academic Department Chair
}

\section{Azim Mirzazadeh}

Tehran university of medical sciences

Mohammad Jalili

Tehran University of Medical Sciences

Akbar Fotouhi

Tehran University of Medical Sciences

nooshin kohan ( $\nabla$ nu.kohan@gmail.com )

Tehran University of Medical Sciences https://orcid.org/0000-0002-8163-742X

\section{Research article}

Keywords: Academic Department Chair, Medical School, Performance Improvement, Conceptual

Framework

Posted Date: November 2nd, 2019

DOI: https://doi.org/10.21203/rs.2.14335/v2

License: (c) (1) This work is licensed under a Creative Commons Attribution 4.0 International License. Read Full License 
The authors have withdrawn this preprint from Research Square 